\title{
Correction to: Correlation between platinum-aluminide coating features and tensile behavior of nickel-based superalloy Rene ${ }^{\circledR} 80$
}

Mohammad Mehdi Barjesteh, Seyed Mehdi Abbasi* ${ }^{(1)}$, Karim Zangeneh Madar, Kourosh Shirvani

(C) The Nonferrous Metals Society of China and Springer-Verlag GmbH Germany, part of Springer Nature 2019

Correction to: Rare Met.

https://doi.org/10.1007/s12598-019-01293-4

In the original publication, Fig. 12 was published incorrectly. The correct version of Fig. 12 is given in this correction.

The original article was corrected.

The original article can be found online at https://doi.org/10.1007/ s12598-019-01293-4.

M. M. Barjesteh, S. M. Abbasi*, K. Z. Madar

Metallic Materials Research Center, Malek Ashtar University of

Technology (MUT), Tehran 158751774, Iran

e-mail: sma_abbasi@mut.ac.ir

K. Shirvani

Department of Advanced Materials and New Energies, Iranian Research Organization for Science and Technology (IROST),

Tehran 3313193685, Iran 

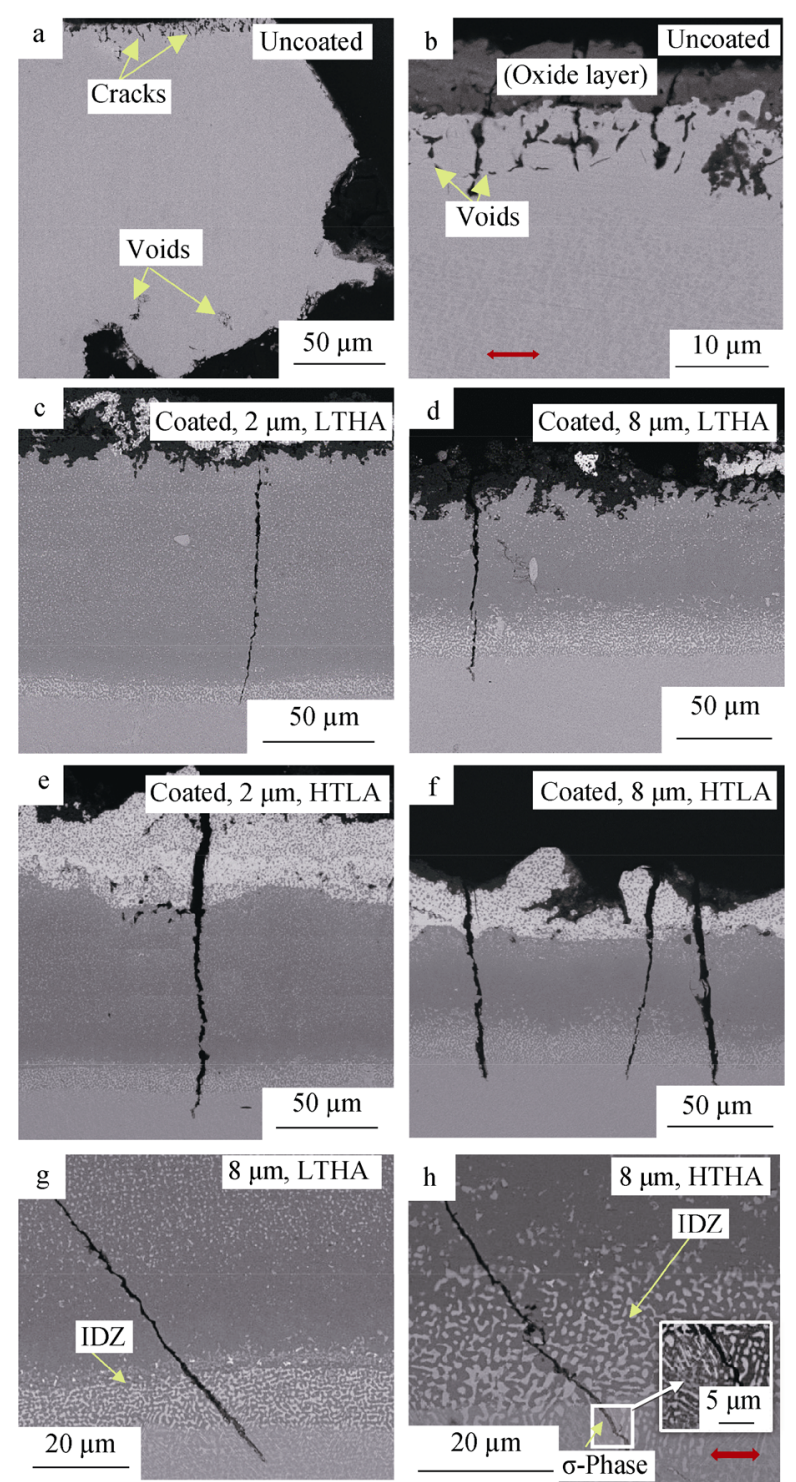

Fig. 12 SEM images of fracture surface (longitudinal section): uncoated tensile samples with $\mathbf{a}$ fracture end and $\mathbf{b}$ cracks initiated from oxide layer; coated samples with platinum layer thicknesses of c $2 \mu \mathrm{m}$ and $\mathbf{d} 8 \mu \mathrm{m}$ in LTHA and e $2 \mu \mathrm{m}$ and $\mathbf{f} 8 \mu \mathrm{m}$ in HTLA methods; IDZ for samples with platinum layer thickness of $8 \mu \mathrm{m}$ in g LTHA and $\mathbf{h}$ HTLA methods (inset being image of needle-like $\sigma$ phase) 